\title{
Comparison of 3-Dimensional Pelvic Floor Ultrasonography and Defecography for Assessment of Posterior Pelvic Floor Disorders
}

\author{
Hong Yoon Jeong, Shi-Jun Yang, Dong Ho Cho, Duk Hoon Park, Jong Kyun Lee \\ Department of Surgery, Seoul Song Do Hospital, Seoul, Korea
}

Purpose: The aim of this study was to determine the accuracy of 3-dimensional (3D) pelvic floor ultrasonography and compare it with defecography in assessment of posterior pelvic disorders.

Methods: Eligible patients were consecutive women undergoing 3D pelvic floor ultrasonography at one hospital between August 2017 and February 2019. All 3D pelvic floor ultrasonography was performed by one examiner. A total of 167 patients with suspected posterior pelvic disorder was retrospectively enrolled in the study. The patients were divided into 3 groups according to the main symptoms.

Results: There were 82 rectoceles on defecography (55 barium trapping) and 84 on 3D pelvic floor ultrasonography. Each modality identified 6 enteroceles. There were 43 patients with pelvic floor dyssynergia on defecography and 41 on ultrasonography. There were 84 patients with intussusception on defecography and 41 on 3D pelvic floor ultrasonography. Agreement of the 2 diagnostic tests was confirmed using Cohen's kappa value. Rectocele (kappa, 0.784) and enterocele (kappa, 0.654) both indicated good agreement between defecography and 3D pelvic floor ultrasonography. In addition, pelvic floor dyssynergia (kappa, 0.406) showed moderate agreement, while internal intussusception (kappa, 0.296) had fair agreement.

Conclusion: This study showed good agreement for detection of posterior pelvic disorders between defecography and 3D pelvic floor ultrasonography.

Keywords: Pelvic floor disorders; Defecography; 3-Dimensional pelvic floor ultrasonography

\section{INTRODUCTION}

The prevalence rate of pelvic floor disorders is approximately $15 \%$ in multiparous women [1]. These disorders generally refer to functional anorectal disturbances; symptoms are often nonspecific and associated with structural, neuromuscular, and functional defects giving rise to symptoms of prolapse, pelvic pressure,

Received: Nov 28, 2019 - Revised: Feb 4, 2020 - Accepted: Feb 9, 2020 Correspondence to: Shi-Jun Yang, M.D.

Department of Surgery, Seoul Song Do Hospital, 72 Dasan-ro, Jung-gu, Seoul 04597, Korea

Tel: +82-2-2250-7368, Fax: +82-2-2233-8528

E-mail : vishnujin84@gmail.com

ORCID: https://orcid.org/0000-0002-3813-4974

(C) 2020 The Korean Society of Coloproctology

This is an open-access article distributed under the terms of the Creative Commons Attribution NonCommercial License (https://creativecommons.org/licenses/by-nc/4.0) which permits unrestricted noncommercial use, distribution, and reproduction in any medium, provided the original work is properly cited. fecal incontinence, stool trapping, and constipation. The symptoms can have a significant impact on quality of life [2]. As women age, these diseases tend to increase in prevalence and therefore require an accurate diagnosis [3]. Identification of posterior pelvic disorders is important for proper treatment planning [4]. The most commonly used imaging modalities today are defecography [5-7], 3-dimensional (3D) pelvic floor ultrasonography [8-14], and magnetic resonance imaging [15-17].

For the last 60 years, defecography has been the gold standard test for evaluating posterior pelvic floor disorders $[5,6]$. Posterior pelvic compartment disorders, such as rectocele, intussusception, dyssynergia, and enterocele, may be evaluated using defecography, although this approach has disadvantages, such as exposing patients to ionizing radiation [7].

In recent years, alternatives to defecography, such as $3 \mathrm{D}$ pelvic floor ultrasonography and dynamic magnetic resonance imaging, have been developed for evaluation of posterior pelvic floor disor- 
ders $[17,18]$. In particular, 3D pelvic floor ultrasonography is fast, effective, noninvasive, and well tolerated [19]. In a prospective multicenter study, 3D pelvic floor ultrasonography was shown to correlate well with conventional defecography [18]. The 3D ultrasonography, which uses a transducer to provide information either in the axial or sagittal plane, is used in conjunction with dynamic 2-dimensional (2D) imaging to enable visualization of the levator ani muscle, urinary tract, and anal sphincter [20].

Literature on 3D pelvic floor ultrasonography has been published only in Western countries. Therefore, the aim of this study was to determine the accuracy of 3D pelvic floor ultrasonography and compare it with defecography in the assessment of posterior pelvic disorders in Korean women.

\section{METHODS}

Eligible patients were consecutive women undergoing 3D pelvic floor ultrasonography at one hospital between August 2017 and February 2019. Demographic and symptom data were recorded retrospectively; age, presenting complaint, parity, previous surgery, and subsequent treatment. These patients were offered a complete workup of their symptoms using anorectal manometry, electromyography (EMG) testing, defecography, and 3D pelvic floor ultrasonography. This study was approved by the Institutional Review Board of Seoul Songdo Hospital (No. 2019-006). The informed consent of patients was waived because of the retrospective nature of the study.

All 3D pelvic floor ultrasonography was performed by one examiner (a colorectal surgeon), and all defecography was analyzed by another experienced colorectal surgeon. A total of 167 patients with suspected posterior pelvic disorder was retrospectively enrolled in the study. The patients were divided into 3 groups according to main symptoms. The constipation group consisted of 64 patients with defecation difficulty and incomplete evacuation. The incontinent group consisted of 69 patients with fecal incontinence and fecal soiling. The last group was the non-bowel dysfunction group, consisting of 34 patients with other symptoms. None of the patients in the non-bowel dysfunction group belonged to either the constipation group or the incontinent group, but all were suspected of posterior pelvic disorder. Symptoms of this group were anal bleeding, discharge, and mass.

\section{Defecography}

The patient was seated on a specially designed chair for examination, and the left side was photographed with fluorescent images (Hitachi Medix 320, Hitachi Ltd., Tokyo, Japan). A rubber tube containing water was placed on the perimeter so that the boundary between the soft tissue of the buttocks and the air could be clearly seen. The photography condition was 82 to $86 \mathrm{Kvp}, 60 \mathrm{~mA}$, and $250 \mathrm{~mA}$ (Hitachi). A diluted barium solution at $60 \%$ weight/ volume $(250 \mathrm{~mL})$ was drunk from 120 to 90 minutes before the test to visualize the small intestine. A condom containing gauze impregnated with barium was placed in the vagina to easily identify the relationship between the front wall of the rectum and the vaginal wall. During the examination, 150 to $200 \mathrm{~mL}$ of highconcentration barium solution at $125 \%$ weight/volume with a consistency similar to stool was injected until the rectosigmoid junction was visible. The images were divided into resting state, squeezing state, and straining state. Anorectal angle, location of the anorectal junction, diameter of the anal canal, change of rectal shape, and residual status of barium in the rectum after defecation were emphasized. Rectocele was defined as a herniation of the rectal wall protruding into the posterior vaginal wall during straining. It was measured perpendicularly to the expected contour of the anterior rectal wall, and a difference greater than $2 \mathrm{~cm}$ was considered rectocele. Enterocele was defined as a hernia into the pouch of Douglas or between the rectum and the vagina and usually contained the small bowel. Nonrelaxation or paradoxical contraction of the puborectalis muscle was considered pelvic floor dyssynergia. Patients with invagination of the rectal wall during straining were diagnosed with internal intussusception.

\section{The 3D pelvic floor ultrasonography}

The 3D pelvic floor ultrasonography was performed with a 3D ultrasound device (Flex Focus, endoprobe model 8838; B-K Medical, Herlev, Denmark) by a single colorectal surgeon (SJY) with experience in 3D ultrasonography. During examination, the patient was placed in the supine position. Pelvic floor images were acquired for all patients through the 5 steps described by Shobeiri et al. [21]. Images consisted of 2D transperineal functional images, 2D endovaginal functional images, 3D endovaginal images, and 3D endoanal images. Rectocele was measured as the maximal depth of the protrusion beyond the expected margin of the normal anterior rectal wall on straining. A herniation greater than 10 $\mathrm{mm}$ was considered diagnostic on sonographic images. Enterocele was defined as a hernia into the pouch of Douglas or between the rectum and the vagina and containing the small bowel. The patient was diagnosed with pelvic floor dyssynergia if, during the Valsalva maneuver, the anorectal angle did not open or became narrower. Internal intussusception was defined as invagination of the rectal wall into the distal lumen [22]. All images were analyzed by an examiner blinded to defecography findings.

\section{Statistical analysis}

The groups were compared according to posterior pelvic floor disorder after being diagnosed by 3D ultrasonography and defecography. Physiologic examinations such as anorectal manometry and electromyography were also compared across groups. Differences between groups were assessed using the Student t-test for noncontinuous data and 1-way analysis of variance for continuous data. Results were considered statistically significant when $\mathrm{P}<0.05$. Cohen's kappa coefficients were calculated to verify the agreement between 3D pelvic floor ultrasonography and defecography in detection of rectocele, enterocele, internal intussusception, and pelvic 
floor dyssynergia. The strength of agreement was interpreted according to the Altman classification system $(<0.20$, poor; 0.21 to 0.40 , fair; 0.41 to 0.60 , moderate; 0.61 to 0.80 , good; and 0.81 to 1.00 , very good) [20]. Data were analyzed using IBM SPSS Statistics, ver. 22.0 for Windows (IBM Corp., Armonk, NY, USA).

\section{RESULTS}

\section{Patient characteristics}

Overall, 167 patients (age: mean, 63 years; range, 30 to 89 years) were included in the study. Sixty-four patients (38.3\%) complained of difficulty in defecation or incomplete evacuation, and $69(41.3 \%)$ complained of fecal incontinence or fecal soiling; the remaining 34 patients (20.4\%) included those with posterior pelvic disorder presenting other symptoms and were diagnosed with non-bowel dysfunction. The symptoms experienced by patients in this third group included anal pain $(5,14.7 \%)$, anal bleeding $(8$, $23.5 \%)$, anal prolapse $(18,52.9 \%)$, and vaginal discharge $(3,8.8 \%)$. Overall, 20 patients $(12.0 \%)$ had urinary incontinence symptoms. Most patients $(152,91.0 \%)$ experienced one or more vaginal deliveries; only 5 (3.0\%) were nulliparous women, while 8 (4.8\%) underwent a cesarean section. Previous pelvic surgeries included hysterectomy $(16,9.6 \%)$, tension-free vaginal tape procedure $(9$, $5.4 \%)$, perineoplasty $(7,4.2 \%)$, and uterine prolapse operations (2, $1.2 \%)$. The number of patients who underwent transvaginal anterior levatorplasty with posterior colporrhaphy was $52(31.1 \%)$, and $41(24.6 \%)$ received medication along with biofeedback and electrical muscle stimulation $(27,16.2 \%)$. Laxative agents were used for patients with defecation difficulty, and loperamide was used in patients with fecal incontinence. Biofeedback and electrical muscle stimulation were performed in patients with posterior pelvic disorders who refused surgery or had minor symptoms (Table 1).

\section{Physiologic examination}

This study compared the results of anorectal manometry, EMG, and pudendal nerve terminal motor latency (PNTML) for 3 groups of patients. The maximal resting pressure according to anorectal manometry (normal range, 64 to $84 \mathrm{mmHg}$ ) of the group that experienced incontinence was $44.12 \pm 11.19 \mathrm{mmHg}$, which was significantly lower than that of the constipated group $(61.08 \pm 16.39 \mathrm{mmHg})$ and the asymptomatic group (64.73 \pm $11.50 \mathrm{mmHg}$ ). In addition, the maximal squeezing pressure (normal range, 75 to $150 \mathrm{mmHg}$ ) of the incontinent group (95.25 \pm $39.36 \mathrm{mmHg}$ ) was significantly lower than that of the constipated group $(118.82 \pm 52.31 \mathrm{mmHg})$. The maximal tolerable volume (normal range, 115 to $170 \mathrm{~mL}$ ) tended to be lower in the incontinent group $(122.63 \pm 31.98 \mathrm{~mL})$; however, this difference was not statistically significant. The EMG and PNTML results were closer to a normal range in the non-bowel dysfunction group; however, there was no significant difference (Table 2).
Table 1. Patient demographics $(n=167)$

\begin{tabular}{lc}
\hline Variable & Value \\
\hline Age (yr) & $63.6 \pm 12.4$ \\
Main presenting complaint & \\
\hline Defecation difficulty, incomplete evacuation & $64(38.3)$ \\
Fecal incontinence, soiling & $69(41.3)$ \\
\hline Non-bowel dysfunction (other symptoms) & $34(20.4)$ \\
Urinary incontinence & $20(12.0)$ \\
Mode of delivery & \\
\hline Nulliparous & $5(3.0)$ \\
\hline At least one vaginal delivery & $152(91.0)$ \\
\hline Cesarean section only & $8(4.8)$ \\
\hline Unknown & $2(1.2)$ \\
Previous pelvic surgery & \\
\hline Hysterectomy & $16(9.6)$ \\
\hline Tension-free vaginal tape & $9(5.4)$ \\
\hline Perineoplasty & $7(4.2)$ \\
\hline Uterine prolapse operation & $2(1.2)$ \\
Treatment & \\
\hline Biofeedback and electrical muscle stimulation & $27(16.2)$ \\
\hline Medication & $41(24.6)$ \\
\hline Transvaginal anterior levatorplasty with posterior colporrhaphy & $52(31.1)$ \\
\hline Follow-up loss & $42(25.1)$ \\
\hline Others & $5(3.0)$ \\
\hline
\end{tabular}

Values are presented as mean \pm standard deviation or number (\%).

aHemorrhoidectomy, reroute operation, and skin flap.

\section{Defecography and 3D pelvic floor ultrasonography}

Rectocele was identified in 82 patients (49.1\%) on defecography (Fig. 1) and was diagnosed significantly more often among patients in the constipated group $(42,65.6 \%)$ than among those in the incontinent $(25,36.2 \%)$ and asymptomatic groups $(15,44.1 \%)$. Enterocele was identified only in the constipated $(3,4.7 \%)$ and incontinent groups $(3,4.3 \%)$ (Fig. 2). In other words, enterocele appeared only in groups with bowel dysfunction. Internal intussusception was diagnosed more commonly in the incontinent group (41, 59.4\%); however, no significant differences in the rates of enterocele and internal intussusception were noted. We also found that barium trapping was more common in the constipated group $(33,51.6 \%)$, and leaks were more common in the incontinent group (37, 53.6\%) (Table 3). Rates of rectocele were higher in the constipated group, and the average rectocele size was also larger $(22.97 \pm 14.07 \mathrm{~mm})$ in this group than in the other groups. On 3D pelvic floor ultrasonography, rectocele was identified in $84 \mathrm{pa}-$ tients (50.3\%) and significantly more so in the constipated group $(42,65.6 \%)$ than in the incontinent $(26,37.7 \%)$ and asymptomatic groups (16, 47.1\%). Although no significant difference was seen, 
Table 2. Results of anorectal manometry and electromyography

\begin{tabular}{|c|c|c|c|c|}
\hline Variable & Constipated group $(n=64)$ & Incontinent group $(n=69)$ & Non-bowel dysfunction group $(n=34)$ & P-value \\
\hline MRP (mmHg) & $61.08 \pm 16.39$ & $44.12 \pm 11.19$ & $64.73 \pm 11.50$ & 0.005 \\
\hline MSP (mmHg) & $118.82 \pm 52.31$ & $95.25 \pm 39.36$ & $93.06 \pm 42.40$ & 0.014 \\
\hline MSV (mL) & $5.63 \pm 1.92$ & $6.02 \pm 2.58$ & $5.60 \pm 1.65$ & 0.142 \\
\hline MTV (mL) & $140.89 \pm 40.50$ & $122.63 \pm 31.98$ & $134.00 \pm 33.16$ & 0.058 \\
\hline Electromyography & 55 & 66 & 27 & 0.217 \\
\hline Normal & $32(58.2)$ & $35(53.0)$ & $20(74.1)$ & \\
\hline Equivocal & $2(3.6)$ & $6(9.1)$ & $0(0.0)$ & \\
\hline Paradoxical & $21(38.2)$ & $25(37.9)$ & $7(25.9)$ & \\
\hline PNTML & 55 & 66 & 28 & 0.187 \\
\hline Normal & $23(41.8)$ & $30(45.5)$ & $16(57.1)$ & \\
\hline Unilateral neuropathy & 21 (38.2) & $17(25.8)$ & $9(32.1)$ & \\
\hline Bilateral neuropathy & $11(20.0)$ & $19(28.8)$ & $3(10.7)$ & \\
\hline
\end{tabular}

Values are presented as mean \pm standard deviation, number only, or number (\%).

MRP, maximal resting pressure; MSP, maximal squeezing pressure; MSV, minimal sensory volume; MTV, maximal tolerable volume; PNTML, pudendal nerve terminal motor latency.
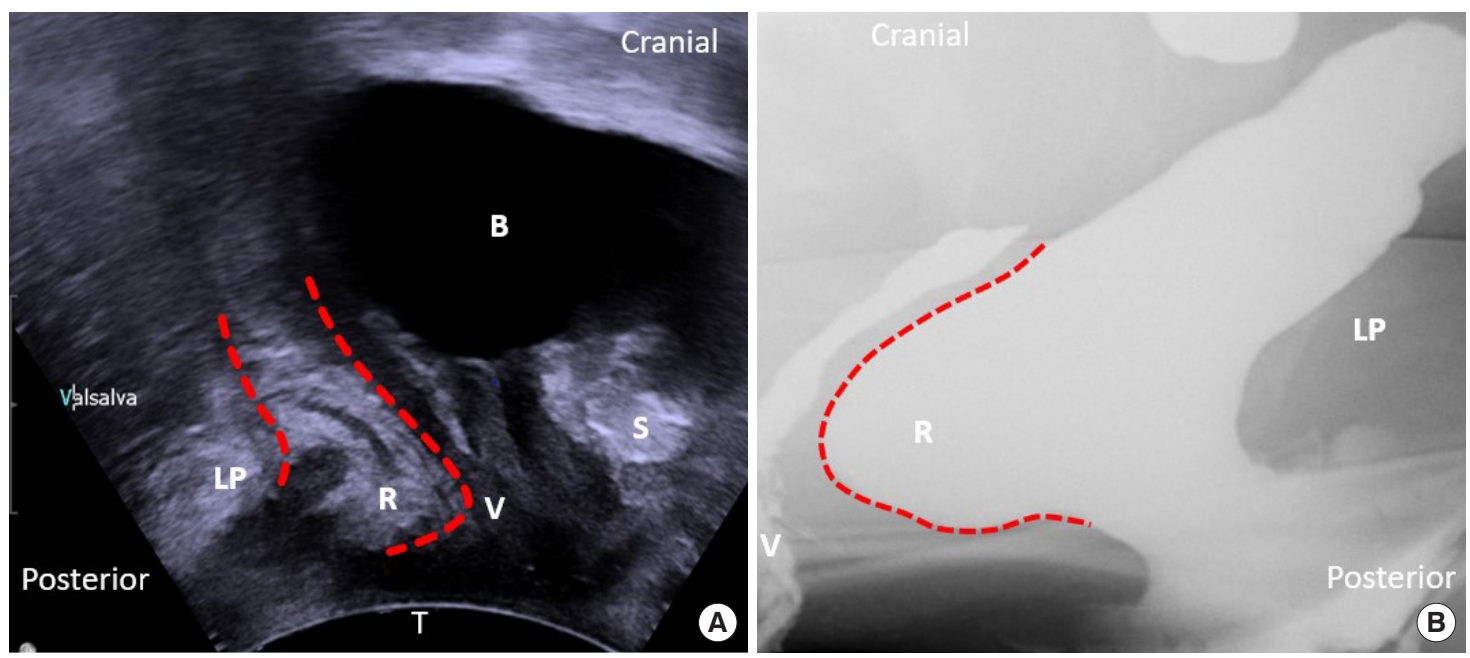

Fig. 1. (A) The 3-dimensional pelvic floor ultrasonography of the rectocele. (B) Defecography of the rectocele. B, bladder; LP, levator plate; R, rectocele; $\mathrm{V}$, vagina; $\mathrm{S}$, pubic symphysis; $\mathrm{T}$, transducer.

many patients in the constipated and incontinent groups were diagnosed with enterocele ( $4.7 \%$ in the constipated group vs. $4.3 \%$ in the incontinent group) or internal intussusception (14.1\% in the constipated group vs. $24.6 \%$ in the incontinent group). Similarly, anal sphincter injuries were common in the constipated group (32.8\% with an internal anal sphincter injury and 35.3\% with an external anal sphincter injury) and the incontinent group (30.4\% with an internal anal sphincter injury and $47.1 \%$ with an external anal sphincter injury); however, the difference between the groups was not statistically significant. As seen, sphincter injuries tended to be more prominent in bowel dysfunction groups, but the difference was not statistically significant (Table 4).

\section{Cohen's kappa value}

The diagnoses of rectocele, enterocele, internal intussusception, and pelvic floor dyssynergia on defecography and/or 3D pelvic floor ultrasonography are shown in Table 5. Agreement of the 2 diagnostic tests was confirmed using Cohen's kappa value. There was good agreement between defecography and 3D pelvic floor ultrasonography in identification of rectocele (kappa, 0.784) and enterocele (kappa, 0.654). In addition, the 2 methods showed moderate agreement in identifying pelvic floor dyssynergia (kappa, 0.406) and fair agreement in identifying internal intussusception (kappa, 0.296) (Table 5). In our study, there were significantly more diagnoses of intussusception with defecography when 

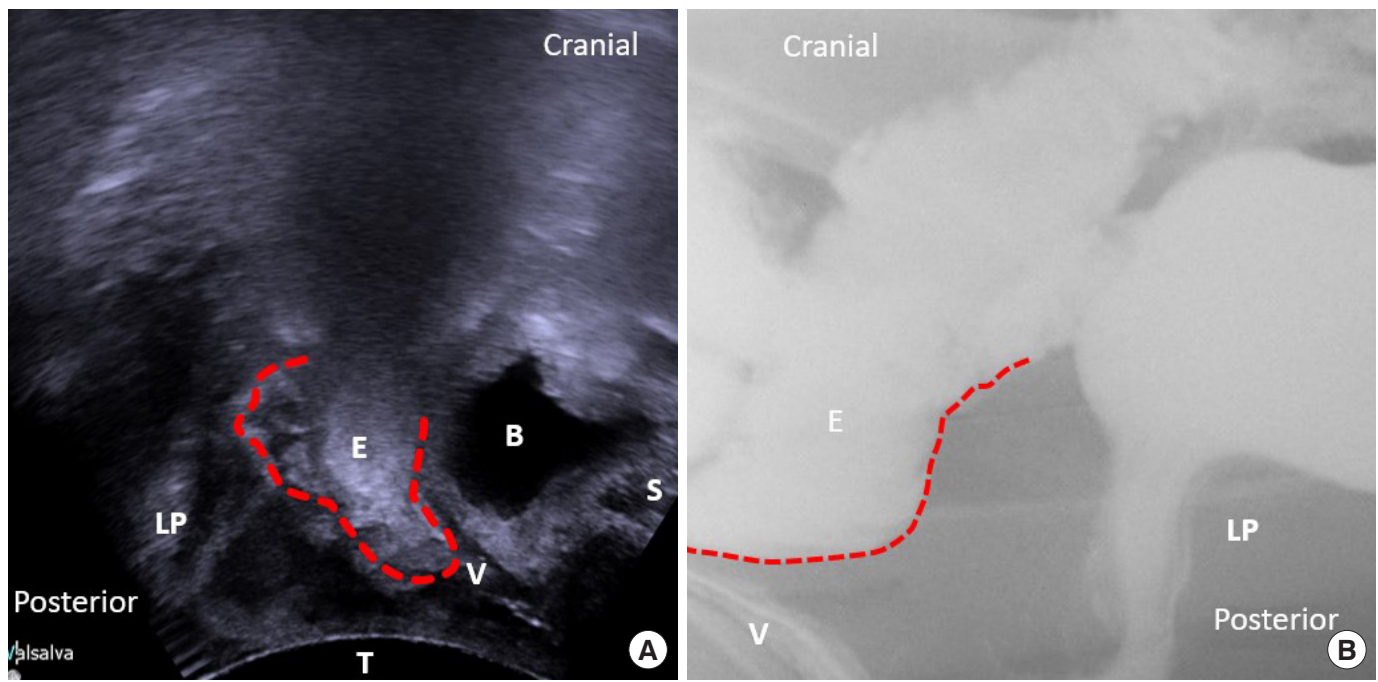

Fig. 2. (A) The 3-dimensional pelvic floor ultrasonography of the enterocele. (B) Defecography of the enterocele. LP, levator plate; E, enterocele; B, bladder; S, pubic symphysis; V, vagina; T, transducer.

Table 3. Results of defecography

\begin{tabular}{lcccc}
\hline Variable & Constipated group $(\mathrm{n}=64)$ & Incontinent group $(\mathrm{n}=69)$ & Non-bowel dysfunction group $(\mathrm{n}=34)$ & $\mathrm{P}$-value \\
\hline Rectocele & $42(65.6)$ & $25(36.2)$ & $15(44.1)$ & 0.003 \\
Rectocele size $(\mathrm{mm})$ & $22.97 \pm 14.07$ & $14.69 \pm 10.97$ & $18.04 \pm 13.43$ & 0.149 \\
Enterocele & $3(4.7)$ & $3(4.3)$ & $0(0)$ & 0.273 \\
Internal intussusception & $29(45.3)$ & $41(59.4)$ & $14(41.2)$ & 0.131 \\
Pelvic floor dyssynergia & $15(23.4)$ & $12(17.4)$ & $6(17.6)$ & 0.642 \\
Barium trapping & $33(51.6)$ & $10(14.5)$ & $12(35.3)$ & $<0.001$ \\
Leak & $9(14.1)$ & $37(53.6)$ & $10(29.4)$ & $<0.001$ \\
\hline
\end{tabular}

Values are presented as number (\%) or mean \pm standard deviation.

Table 4. Results of 3-dimensional ultrasonography

\begin{tabular}{lcccc}
\hline Variable & $\begin{array}{c}\text { Constipated } \\
\text { group } \\
(\mathrm{n}=64)\end{array}$ & $\begin{array}{c}\text { Incontinent } \\
\text { group } \\
(\mathrm{n}=69)\end{array}$ & $\begin{array}{c}\text { Non-bowel } \\
\text { dysfunction } \\
\text { group } \\
(\mathrm{n}=34)\end{array}$ & P-value \\
\hline Rectocele & $42(65.6)$ & $26(37.7)$ & $16(47.1)$ & 0.005 \\
Enterocele & $3(4.7)$ & $3(4.3)$ & $0(0)$ & 0.273 \\
Internal intussusception & $9(14.1)$ & $17(24.6)$ & $5(14.7)$ & 0.237 \\
Pelvic floor dyssynergia & $12(18.8)$ & $11(15.9)$ & $6(17.6)$ & 0.912 \\
IAS injury & $21(32.8)$ & $21(30.4)$ & $7(20.6)$ & 0.434 \\
EAS injury & $24(37.5)$ & $32(46.4)$ & $12(35.3)$ & 0.448 \\
Avulsion & $7(10.9)$ & $5(7.2)$ & $3(8.8)$ & 0.808 \\
\hline
\end{tabular}

Values are presented as number (\%).

IAS, internal anal sphincter; EAS, external anal sphincter.

the 2 tests were compared. However, for rectocele, enterocele, and pelvic floor dyssynergia, the numbers of patients diagnosed using defecography or 3D pelvic floor ultrasonography were similar.
Table 5. Cohen's kappa value showing the difference between defecography and 3-dimensional (3D) ultrasonography

\begin{tabular}{lrrc}
\hline \multirow{2}{*}{3 ultrasonography } & \multicolumn{2}{c}{ Defecography } & \multirow{2}{*}{$\begin{array}{c}\text { Cohen's kappa } \\
\text { value }\end{array}$} \\
\cline { 2 - 3 } Rectocele & No & Yes & 0.784 \\
$\quad$ No & 75 & 8 & \\
Yes & 10 & 74 & \\
Enterocele & & & 0.654 \\
$\quad$ No & 159 & 2 & \\
Yes & 2 & 4 & \\
Internal intussusception & & & 0.296 \\
No & 80 & 56 & \\
Yes & 3 & 28 & \\
Pelvic floor dyssynergia & & & 0.406 \\
No & 121 & 17 & \\
Yes & 13 & 16 & \\
\hline
\end{tabular}


Table 6. Overview of literature

\begin{tabular}{lcccc}
\hline Study & $\begin{array}{c}\text { Patients' } \\
\text { No. }\end{array}$ & $\begin{array}{c}\text { Enterocele } \\
(\kappa)\end{array}$ & $\begin{array}{c}\text { Rectocele } \\
(\kappa)\end{array}$ & $\begin{array}{c}\text { Intussusception } \\
(\kappa)\end{array}$ \\
\hline Beer-Gabel et al. [11] & 33 & 0.7 & 0.88 & 0.88 \\
Grasso et al. [23] & 43 & $\mathrm{ND}$ & 0.41 & 0.91 \\
Beer-Gabel et al. [24] & 62 & 0.78 & 0.78 & $\mathrm{ND}$ \\
Perniola et al. [25] & 37 & $\mathrm{ND}$ & 0.26 & 0.09 \\
Steensma et al. [26] & 75 & 0.65 & 0.55 & 0.21 \\
Present study & 167 & 0.65 & 0.78 & 0.29 \\
\hline
\end{tabular}

$\kappa$, Cohen's kappa coefficient index; ND, not detected.

\section{DISCUSSION}

This study showed good agreement between defecography and 3D pelvic floor ultrasonography for diagnosing enterocele and rectocele, moderate agreement for detecting pelvic floor dyssynergia, and fair agreement for detecting intussusception. The level of agreement for rectocele and enterocele was comparable with results recently reported by other authors (Table 6) [11, 23-26]. However, regarding intussusception detection, varying Cohen's kappa values have been reported. These differences may be explained by selection bias; 3 studies $[11,24,25]$ included only patients with longstanding complaints of obstructed defecation. This contrasts with our study and another study [26] that included all patients with symptoms of posterior pelvic disorders. In addition, our study showed a low diagnosis rate for intussusception with 3D pelvic floor ultrasonography. This may be explained by use of contrast material, position of the patient during the study, and lack of patient cooperation, which may cause more internal intussusception to appear in defecography than in 3D pelvic floor ultrasonography. Defecography utilizes an intrarectal barium contrast and can involve compression of the rectovaginal space by overdistension of the rectum can. The sensation of rectal filling may help the process of rectal evacuation by consciously stimulating the patients to strain. Furthermore, defecography has the advantage of placing the patients in a sitting position, which facilitates rectal evacuation [27]. This contrasts with 3D pelvic floor ultrasonography, which is performed in the supine position, possibly hampering the physiologic process of defecation. In some cases, straining may not be performed well due to lack of patient cooperation.

The female pelvic floor includes all of the structures within the bony pelvis. It thus includes not only the lower urinary tract, reproductive tract, and lower gastrointestinal tract, but also the neuromuscular components of their support. "Pelvic floor disorders" have different meanings for the wide range of clinicians who address these problems, including urologists, gynecologists, and colorectal surgeons [28]. There also seems to be limited overlap in the way the disorders are perceived by clinicians. This may cause confusion in diagnosis and treatment of the disorders, which are often complex and associated with structural, neuromuscular, and functional defects. Further, there is no single investigation modality that provides a definitive diagnosis for pelvic floor disorders, which makes diagnoses difficult.

Posterior pelvic disorders generally refer to functional anorectal disturbances and associated symptoms. Posterior pelvic disorders involving bowel dysfunction include several clinical problems such as fecal incontinence, constipation, and rectal prolapse. One of the most common complaints of patients who visit colorectal surgeons is constipation. Pelvic outlet obstruction is a common cause of constipation and is attributed to muscular dysfunction of the pelvic floor [22]. Pelvic outlet obstruction is the inability to evacuate stools from the rectum, caused by anatomic (rectocele, enterocele, and intussusception) or functional (pelvic floor dyssynergia) conditions of the posterior pelvic floor.

Pelvic outlet obstruction is a common multifactorial disorder of the defecation process involving multiple pelvic floor and perineal soft-tissue anomalies [29]. It is characterized by an impaired ability to satisfactorily evacuate the rectum, with a feeling of incomplete evacuation. Despite its increasing frequency, the pathophysiology is poorly understood. Therefore, treatment is available but not always satisfactory. As our understanding of these disorders improves, more successful and more durable treatments will likely develop. Detailed patient history and clinical examination were previously considered the cornerstone of posterior pelvic disorder diagnoses; however, such techniques are relatively insensitive, and there is a general agreement that treatment decisions should be based on imaging assessments. Currently, there is no single imaging investigation that provides a definitive diagnosis for posterior pelvic disorders.

Historically, conventional defecography has been considered the reference standard for posterior pelvic floor disorder assessments because it evaluates in real time any morphological and functional abnormalities of the rectum and anal canal [30]. Identification of the underlying pathology on defecography allows the physician to correlate it with the anatomic abnormality. Defecography may be particularly useful when there is a high index of suspicion for a significant rectocele, an enterocele, and internal rectal intussusception [11]. However, conventional defecography has some disadvantages: it is known to overdiagnose conditions in asymptomatic volunteers and has significant interobserver variability. Therefore, this diagnostic modality should be interpreted with caution. Furthermore, defecography requires ionizing radiation and bowel preparation and can be embarrassing due to the patient having to evacuate contrast in a nonprivate setting. In addition, defecography does not provide any soft-tissue details [29].

Since the introduction of ultrasonography in 1992, it has become increasingly important in many diagnostic areas. In recent years, numerous studies have been published on the usefulness of ultrasound methods for assessing pelvic floor disorders [24, 28, 31 ]. In contrast to conventional defecography, 3D pelvic floor ultrasonography has the advantages of availability and simplicity [8]. 
Patients find 3D pelvic floor ultrasonography more acceptable because of its low cost and short inspection time without unpleasant examination. The major advantage of $3 \mathrm{D}$ pelvic floor ultrasonography in comparison with defecography is the lack of ionizing radiation. This is even more important for female patients of reproductive age. The noninvasive nature and nonionizing radiation of the technique will allow investigations into the prevalence of morphological abnormalities in asymptomatic women and will also allow repeatability of findings. Moreover, 3D pelvic floor ultrasonography could be used to visualize all 3 compartments of the pelvis. Diagnosis of anterior and midcompartment disorders can be confirmed simultaneously and directly by identifying anatomical structures of the posterior pelvic floor [28]. Ultrasonography is also an accepted modality for evaluation of several conditions, including fecal incontinence and benign and malignant anorectal disorders. Endoanal sonography is reliable in assessing sphincter defects and is often used in evaluation of patients with fecal incontinence. Several studies have revealed good reproducibility and similar excellent interobserver reliability rates for detection of anal sphincter defects [32]. In our study, 3D pelvic floor ultrasonography identified anal sphincter injuries and levator ani muscle avulsion for all groups.

This is the first study in Korea to compare defecography and 3D pelvic floor ultrasonography. In addition, the number of patients in our study was much higher than in other studies. However, our study has several limitations. Ultrasound is performed with patients in a supine position; this along with the pressure of the probe to the perineum can yield variable results. The abnormality in question is made visible by performing the Valsalva maneuver, and the test involves actual defecation in a semiprivate setting. For this method, patient cooperation is very important. It has been argued that the Valsalva maneuver is unlikely to replicate normal evacuation owing to stress and embarrassment. Defecography is undertaken in the sitting position. In contrast to defecography that tends to overdiagnose, $3 \mathrm{D}$ pelvic floor ultrasonography tends to underdiagnose. A major limitation is the absence of surgical examination as the reference standard in determination of posterior pelvic disorders. The number of patients who underwent surgery was only $52(31.1 \%)$, and 42 patients (25.1\%) were lost to follow-up. Therefore, it is unclear whether the differences between defecography and 3D pelvic floor ultrasonography imply under- or overdiagnosis by one of these imaging techniques. Furthermore, evaluation of 3D pelvic floor ultrasonography was performed directly by one surgeon, blinded against all clinical data. Comparing the 3D pelvic floor ultrasound analyses of the 2 investigators, interobserver agreement was not obtained.

In conclusion, this study showed good agreement between defecography and 3D pelvic floor ultrasonography for detection of posterior pelvic disorders. Overall, 3D pelvic floor ultrasonography is fast, effective, noninvasive, and well-tolerated. Therefore, 3D pelvic floor ultrasonography may be useful as an initial test or screening method and for diagnosis of posterior pelvic disorders.
Sonographic imaging has been performed by radiologists since its introduction in Korea. If surgeons performed imaging investigations with 3D pelvic floor ultrasonography, they would be able to quickly understand the complete clinical status of their patients, which could enable them to better tailor patient management and could also aid in performing patient-specific surgeries.

\section{CONFLICT OF INTEREST}

No potential conflict of interest relevant to this article was reported.

\section{ACKNOWLEDGMENTS}

The research was supported (in part) by The Seoul Songdo Hospital. The authors would like to express our appreciation to the doctors of Seoul Song Do Hospital.

\section{REFERENCES}

1. Silva AC, Maglinte DD. Pelvic floor disorders: what's the best test? Abdom Imaging 2013;38:1391-408.

2. Davis K, Kumar D. Posterior pelvic floor compartment disorders. Best Pract Res Clin Obstet Gynaecol 2005;19:941-58.

3. Luber KM, Boero S, Choe JY. The demographics of pelvic floor disorders: current observations and future projections. Am J Obstet Gynecol 2001;184:1496-503.

4. Murad-Regadas SM, dos Santos D, Soares G, Regadas FS, Rodrigues $\mathrm{LV}$, Buchen $\mathrm{G}$, et al. A novel three-dimensional dynamic anorectal ultrasonography technique for the assessment of perineal descent, compared with defaecography. Colorectal Dis 2012; 14:740-7.

5. Wald A, Caruana BJ, Freimanis MG, Bauman DH, Hinds JP. Contributions of evacuation proctography and anorectal manometry to evaluation of adults with constipation and defecatory difficulty. Dig Dis Sci 1990;35:481-7.

6. Mahieu P, Pringot J, Bodart P. Defecography: I. description of a new procedure and results in normal patients. Gastrointest Radiol 1984;9:247-51.

7. Bartram CI, Turnbull GK, Lennard-Jones JE. Evacuation proctography: an investigation of rectal expulsion in 20 subjects without defecatory disturbance. Gastrointest Radiol 1988;13:72-80.

8. Barthet M, Portier F, Heyries L, Orsoni P, Bouvier M, Houtin D, et al. Dynamic anal endosonography may challenge defecography for assessing dynamic anorectal disorders: results of a prospective pilot study. Endoscopy 2000;32:300-5.

9. Dietz HP, Haylen BT, Broome J. Ultrasound in the quantification of female pelvic organ prolapse. Ultrasound Obstet Gynecol 2001; 18:511-4.

10. Van Outryve SM, van Outryve MJ, de Winter BY, Pelckmans PA. Is anorectal endosonography valuable in dyschesia? Gut 2002;51: 695-700. 
11. Beer-Gabel M, Teshler M, Schechtman E, Zbar AP. Dynamic transperineal ultrasound vs. defecography in patients with evacuatory difficulty: a pilot study. Int J Colorectal Dis 2004;19:60-7.

12. Dietz HP, Steensma AB. Posterior compartment prolapse on twodimensional and three-dimensional pelvic floor ultrasound: the distinction between true rectocele, perineal hypermobility and enterocele. Ultrasound Obstet Gynecol 2005;26:73-7.

13. Murad-Regadas SM, Regadas FS, Rodrigues LV, Souza MH, Lima DM, Silva FR, et al. A novel procedure to assess anismus using three-dimensional dynamic anal ultrasonography. Colorectal Dis 2007;9:159-65.

14. Murad-Regadas SM, Regadas FS, Rodrigues LV, Silva FR, Soares FA, Escalante RD. A novel three-dimensional dynamic anorectal ultrasonography technique (echodefecography) to assess obstructed defecation, a comparison with defecography. Surg Endosc 2008;22:974-9.

15. Lienemann A, Anthuber C, Baron A, Kohz P, Reiser M. Dynamic MR colpocystorectography assessing pelvic-floor descent. Eur Radiol 1997;7:1309-17.

16. Kaufman HS, Buller JL, Thompson JR, Pannu HK, DeMeester SL, Genadry RR, et al. Dynamic pelvic magnetic resonance imaging and cystocolpoproctography alter surgical management of pelvic floor disorders. Dis Colon Rectum 2001;44:1575-84.

17. Dvorkin LS, Hetzer F, Scott SM, Williams NS, Gedroyc W, Lunniss PJ. Open-magnet MR defaecography compared with evacuation proctography in the diagnosis and management of patients with rectal intussusception. Colorectal Dis 2004;6:45-53.

18. Regadas FS, Haas EM, Abbas MA, Marcio Jorge J, Habr-Gama A, Sands D, et al. Prospective multicenter trial comparing echodefecography with defecography in the assessment of anorectal dysfunction in patients with obstructed defecation. Dis Colon Rectum 2011;54:686-92.

19. Martellucci J, Naldini G. Assessment of posterior compartment prolapse; a comparison of evacuation proctography and 3D transperineal ultrasound. Colorectal Dis 2010;12:834.

20. Wieczorek AP, Stankiewicz A, Santoro GA, Wozniak MM, Bogusiewicz M, Rechberger T. Pelvic floor disorders: role of new ultrasonographic techniques. World J Urol 2011;29:615-23.

21. Shobeiri SA, Leclaire E, Nihira MA, Quiroz LH, O’Donoghue D. Appearance of the levator ani muscle subdivisions in endovaginal three-dimensional ultrasonography. Obstet Gynecol 2009;114:66-
72.

22. Martellucci J, Brusciano L. The dynamic transperineal ultrasound era of the evaluation of obstructed defecation syndrome. Dis Colon Rectum 2016;59:800-3.

23. Grasso RF, Piciucchi S, Quattrocchi CC, Sammarra M, Ripetti V, Zobel BB. Posterior pelvic floor disorders: a prospective comparison using introital ultrasound and colpocystodefecography. Ultrasound Obstet Gynecol 2007;30:86-94.

24. Beer-Gabel M, Assoulin Y, Amitai M, Bardan E. A comparison of dynamic transperineal ultrasound (DTP-US) with dynamic evacuation proctography (DEP) in the diagnosis of cul de sac hernia (enterocele) in patients with evacuatory dysfunction. Int J Colorectal Dis 2008;23:513-9.

25. Perniola G, Shek C, Chong CC, Chew S, Cartmill J, Dietz HP. Defecation proctography and translabial ultrasound in the investigation of defecatory disorders. Ultrasound Obstet Gynecol 2008;31:567-71.

26. Steensma AB, Oom DM, Burger CW, Schouten WR. Assessment of posterior compartment prolapse: a comparison of evacuation proctography and $3 \mathrm{D}$ transperineal ultrasound. Colorectal Dis 2010;12:533-9.

27. Beer-Gabel M, Carter D. Comparison of dynamic transperineal ultrasound and defecography for the evaluation of pelvic floor disorders. Int J Colorectal Dis 2015;30:835-41.

28. Dietz HP, Beer-Gabel M. Ultrasound in the investigation of posterior compartment vaginal prolapse and obstructed defecation. Ultrasound Obstet Gynecol 2012;40:14-27.

29. Bolog N, Weishaupt D. Dynamic MR imaging of outlet obstruction. Rom J Gastroenterol 2005;14:293-302.

30. Shorvon PJ, Marshall MM. Evacuation proctography. In: Wexner SD, Pescatori M, Zbar AP, editors. Complex anorectal disorders investigation and management. London: Springer-Verlag London Limited; 2005. p. 171-98.

31. Martellucci J, Naldini G. Clinical relevance of transperineal ultrasound compared with evacuation proctography for the evaluation of patients with obstructed defaecation. Colorectal Dis 2011;13: 1167-72.

32. Lee JH, Pretorius DH, Weinstein M, Guaderrama NM, Nager CW, Mittal RK. Transperineal three-dimensional ultrasound in evaluating anal sphincter muscles. Ultrasound Obstet Gynecol 2007;30:201-9. 